\title{
WHAT INFLUENCES THE REFERENTIAL PROPERTIES OF REFLEXIVES AND PRONOUNS IN FINNISH?*
}

\author{
Elsi Kaiser, \\ University of Southern California \\ elsi.kaiser@usc.edu \\ Jeffrey T. Runner, Rachel S. Sussman and Michael K. Tanenhaus, \\ University of Rochester
}

\begin{abstract}
According to standard Binding Theory, pronouns and reflexives are in (nearly) complementary distribution. However, representational NPs (e.g. 'picture of her/herself') allow both. It has been suggested that in English, reflexives in representational NPs (RNPs) have a preference for 'sources of information' and that pronouns prefer 'perceivers of information.' We conducted two experiments investigating the effects of structural and non-structural (source/perceiver) factors on the interpretation of two kinds of RNP structures in a typologically different language, namely Finnish. Our results reveal source/perceiver effects for postnominal but not for prenominal RNPs in Finnish, with a difference in the degree of sensitivity that pronouns and reflexives exhibit to the source/perceiver manipulation, and our results also suggest that morphological differences in Finnish reflexives correspond to interpretation differences. As a whole, these results support a multiple-factor model of reference resolution, which assumes that multiple factors can play a role in reference resolution and that the relative contributions of these factors can be different for different anaphoric forms (Kaiser 2003b, Kaiser \& Trueswell in press).
\end{abstract}

\section{Introduction}

According to standard binding theory, pronouns and reflexives are in (nearly) complementary distribution. This complementarity breaks down in representational NPs (e.g. picture of $\{$ her/herself\}), and it has been suggested that in English, non-Binding Theory compatible reflexives in representational NPs are acceptable if they refer to "sources-of-information" (e.g. Kuno 1987) and pronouns with local antecedents are acceptable if they refer to "perceivers-of-information" (Tenny 2004). Psycholinguistic experiments support these claims for English (Kaiser, Runner, Sussman \& Tanenhaus 2005, in press). In this paper, we present two experiments investigating whether these claims hold for a typologically different language, Finnish, whether they arise in more than one structural domain, and whether morphological differences in Finnish reflexives correspond to interpretational differences.

The structure of this paper is as follows. In Section 1.1, we discuss the basics of Binding Theory, and in Section 1.2 we turn to some of the structures where traditional Binding Theory runs into trouble, including so-called representational noun phrases. Section 1.3 considers some of the non-structural factors that have been argued to influence anaphor resolution in cases where Binding Theory is not sufficient. Section 2 summarizes the psycholinguistic work we have conducted on English, investigating the role of nonstructural factors in anaphor resolution, and Sections 3 and 4 present the experiments we conducted on Finnish. Section 5 is the conclusion.

\footnotetext{
${ }^{*}$ We gratefully acknowledge support from NSF grant BCS-0110676 and NIH grant HD-27206.
} 


\subsection{Basics of Binding Theory}

It is well known that pronominal and reflexive noun phrases in English have a nearly complementary distribution, as illustrated in (1).

(1) a. Julius saw $_{\text {him }} *_{\mathrm{i} / \mathrm{j}}$.

b. Julius saw himself $_{\mathrm{i} / *_{\mathrm{j}} \text {. }}$.

c. Julius $s_{i}$ saw a picture of him $*_{i} / j$.

d. Julius $\mathrm{i}_{\mathrm{i}}$ saw a picture of himself $\mathrm{i}_{\mathrm{i} / \mathrm{j}}$.

Principles A and B of Chomskyan Binding Theory (BT) offer a structural account of this complementarity (e.g. Chomsky 1981, 1986). Principle A states that an anaphor (a reflexive pronoun) must be bound (by a c-commanding antecedent) in a local domain, whereas Principle B states that a pronoun must be free in a local domain. For the purposes of this paper, we can simply regard the clause as the relevant local domain. For the most part, we will use the term 'reflexive' rather than 'anaphor', but the two terms can be regarded as synonymous.

\subsection{Where traditional Binding Theory runs into trouble}

Although Binding Theory captures many of the configurations in which reflexives and pronouns can and cannot appear, it has been known for a long time that there are certain structures where the predicted complementarity between pronouns and reflexives does not arise. Some naturally-occurring examples of non-Binding Theory compatible reflexives (reflexives without local antecedents) are given in (2), and examples of non-Binding Theory compatible pronouns (pronouns with local antecedents) are in (3).

(2) a. Bismarck's impulsiveness has, as so often, rebounded against himself. (quoted in Zribi-Hertz 1989)

b. Warren says it's a good time to be an astrophysicist. Fifteen years ago, "we were starved for observations," he says. Now it's the opposite: Theorists like himself are drowning in data from modern telescopes. (from The New Mexican newspaper in Santa Fe, NM, 6/28/04)

(3) a. Poor John. Now he's got an ambitious little snake next to him.

(www.freerepublic.com/ regulator/in-forum)

b. Except he could not throw the ball because he was getting tackled. He was about to hit the ground. He had to do something else. He saw someone behind him. He flipped the ball in desperation. (www.wildbillschiefs.com/news/data/604.txt)

The existence of such examples raises the question of what guides the choice of one form over the other in these contexts. This question has been investigated by a number of researchers, focusing primarily on English (e.g. Cantrall 1974, Kuno 1987, Zribi-Hertz 1989, Pollard \& Sag 1992, Reinhart \& Reuland 1993, Tenny 1996, 2003, 2004), who have suggested that choice of referential form in these contexts is influenced by semantic and/or discourse factors.

In this paper we will focus on a subclass of structures known to be problematic for standard Binding Theory, so-called representational NPs (RNPs), e.g. 'a picture of her/herself', 'a story about him/himself', which are well-known for showing clear discourse/semantic effects ${ }^{1}$ for

\footnotetext{
${ }^{1}$ We often use the hybrid label 'discourse/semantic factors' when discussing the effects of non-structural factors on pronouns and reflexives. One could argue that the source/perceiver manipulation to be discussed below is a semantic, thematic role manipulation. However, it could also be argued that source/perceiver is related to
} 
both pronouns and reflexives (e.g. Kuno 1987, Pollard \& Sag 1992, Reinhart \& Reuland 1993, Keller \& Asudeh 2001, Tenny 2003).

Let us first consider reflexives in RNPs. Strikingly, example (4a) is acceptable, although the antecedent of 'himself' is not in the same sentence as the reflexive, and thus cannot bind 'himself'. The contrast between (4a) and (4b) (both from Pollard \& Sag 1992) shows that pragmatic factors such as 'point of view' can have a strong influence on the acceptability of such reflexives. Example (4a) is judged to sound better than (4b), and Pollard \& Sag suggest that this is because (4a) - but not $(4 b)$ - is from John's point of view. In other words, it appears that reflexives referring to 'point of view'-antecedents are acceptable, even if the antecedent does not bind the reflexive as required by Binding Theory.

(4) a. $J \mathrm{ohn}_{\mathrm{i}}$ was going to get even with Mary. [That picture of himimimself $\mathrm{f}_{\mathrm{i}}$ ] in the paper would really annoy her, as would the other stunts he had planned.

b. Mary was quite taken aback by the publicity $\mathrm{John}_{\mathrm{i}}$ was receiving. [That picture of $\operatorname{him}_{\mathrm{i}} /{ }^{*}$ himself $\left._{\mathrm{i}}\right]$ in the paper would really annoy her, as would the other stunts he had planned.

More generally, Kuno (1987) argues that factors like point of view, awareness and semantic roles influence whether a given entity can act as the antecedent for a non-BT compatible reflexive (see also Pollard \& Sag 1992, Reinhart \& Reuland 1993). We focus on the hypothesis in (6), based on Kuno's claims (see his example (5)) and drawing on Sells (1987)'s definition of source as the one who is the intentional agent of the communication

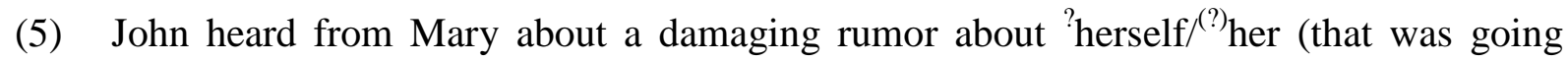
around). (Kuno 1987:175)

(6) Hypothesis for reflexives: BT-incompatible reflexives in RNPs are acceptable if they refer to sources-of-information.

Let us now turn to the question of what kinds of pragmatic factors have been claimed to influence pronouns in RNPs. According to standard Binding Theory, none of the examples in (7) (based on Reinhart \& Reuland 1993) should be grammatical, since in each case the pronoun is c-commanded by a local antecedent.

(7) a. Lucie $_{i}$ saw the picture of her.

c. Max $_{i}$ heard the story about himi . b. ${ }^{*}$ Lucie $_{\mathrm{i}}$ took the picture of her $\mathrm{i}_{\mathrm{i}}$

d. $*$ Max $_{\mathrm{i}}$ told the story about himi .

However, (7a) and (7c) tend to be judged as more acceptable than (7b) and (7d). Tenny (2003) calls these kinds of pronouns short-distance pronouns (SDPs) and notes that "verbs that provide a sentient, perceiving antecedent are especially conducive to SDPs" (Tenny 2003:42). She continues that "....SDPs in representational contexts [.....] are especially felicitous with perceiving subjects" (Tenny 2003:42). In light of this claim, it is not surprising that (7a) and (7c) are judged to sound better, since in both cases the antecedent is a perceiver. Thus, for pronouns we investigate the hypothesis in (8):

(8) Hypothesis for pronouns: BT-incompatible pronouns in RNPs are acceptable if they refer to perceivers-of-information.

Although Kuno and Tenny do not comment on this, the hypotheses in (6) and (8) can be regarded, in some sense, as 'two sides of the same coin' - given that verbs like tell/hear involve both a source-of-information and a perceiver-of-information. Thus, it might turn out to be the case that BT-incompatible pronouns and reflexives have a (non-structurally driven) complementary distribution. 


\subsection{What kinds of information contribute to anaphor resolution?}

The more general theme underlying our investigation of pronouns and reflexives in RNPs concerns the question of what kind of information contributes to reference resolution - in particular, how structural and non-structural information interact in the course of reference resolution. RNPs provide an ideal tool to further test the 'multiple-factor model' of reference resolution argued for by Kaiser (2003b) and Kaiser \& Trueswell (in press). According to this approach, different referential forms are sensitive to different kinds of information (e.g. syntactic, semantic, discourse) to different degrees. For example, certain referential forms are primarily sensitive to syntactic factors, whereas others are influenced mainly by discourselevel factors such as referent salience. In other words, the claim is that the relative contributions of different factors for each referential form can vary. Kaiser (2003b) (see also Kaiser \& Trueswell, in press; Brown-Schmidt, Byron \& Tanenhaus, 2005) argues in favor of the multiple-factor model on the basis of reference resolution across clauses in Finnish, Dutch and Estonian, and RNPs provide an ideal tool for testing whether the same model can be applied to reference resolution within clauses, which is a domain that has traditionally been regarded as more constrained by syntactic factors than across-clause reference resolution.

In this paper, we compare the predictions of a multiple-factor approach (which we will refer to as an interactive/modulation view in this paper) to those of two 'single-factor' approaches, which we will refer to as the pure structural view and the pure discourse/semantic view. We focus on the interpretation of pronouns and reflexives in sentences such as those in (9):

(9) a. Peter told Andrew about the picture of $\{$ him/himself $\}$ on the wall.

b. Peter heard from Andrew about the picture of $\{$ him/himself $\}$ on the wall.

According to the pure structural view, only syntactic factors are relevant for determining the antecedents of pronouns and reflexives, and differences only on the level of verb semantics do not lead to differences in binding patterns. The prediction is that reflexives always refer to local c-commanding antecedents (here, subjects) and pronouns to non-commanding antecedents (here, objects; see also footnote 2). In contrast, the other extreme of the scale is the pure discourse/semantic view, according to which the antecedents of pronouns and demonstratives in RNPs are determined on basis of discourse/semantic role only. According to this approach, reflexives are predicted to refer to sources of information (e.g. the subject of 'tell' and the object of 'hear') and pronouns to perceivers of information (e.g. the subject of 'hear' and the object of 'tell') - regardless of grammatical role. Finally, according to the interactive/modulation view (which assumes that multiple factors can be relevant), both structure and discourse/semantics play a role. The predictions are, therefore, that reflexives will have more non-BT compatible object-antecedents with 'hear' than with 'tell' (since the object is the source with 'hear'), and pronouns will have more non-BT compatible subject with 'hear' than 'tell' perceivers than sources (since the subject is the perceiver with 'hear').

\section{Representational NPs in English: Previous work}

In earlier experimental work (Kaiser, Runner, Sussman \& Tanenhaus 2005, in press), we explored the three hypotheses sketched out in section 1.3 for pronouns in picture NP constructions in English (ex.(9)). We opted to investigate these issues experimentally because judgments concerning these kinds of constructions are notoriously variable. With an experimental approach, we can manipulate the structural and pragmatic/semantic variables that we are interested in test, and we can collect a set of data from a large group of participants that can then be statistically analyzed to see whether there are any reliable patterns. In addition, using eye-tracking methodology (see Kaiser et al. in press), we can obtain incremental, real-time information about interpretation. Thus, we obtain information about participants' final referential choices and also about the possible referents they consider 
before they make a choice. These kinds of data can shed further light on the nature of the relation between syntactic and discourse/semantic factors in anaphora resolution.

Our results show that the interpretation of pronouns and reflexives in RNPs in English is influenced by the source/perceiver manipulation. More specifically, pronouns exhibit a strong preference for perceivers, and reflexives show a weaker preference for sources. Thus, as a whole the results support the modulation view, which posits that both structural and discourse/semantic information play a role in the processing and interpretation of pronouns and reflexives in RNPs. Furthermore, as the asymmetrical nature of the results reveals, the effects are not equally strong for reflexives and pronouns. Pronouns display a much greater sensitivity to non-structural factors. This supports Kaiser (2003b)'s multiple-factor model, which claims that not only are multiple factors relevant, but the relative contributions of different factors for each referential form can vary. In other words, the Kaiser et al. (in press) results show that in English, the relative strength of discourse/semantic factors, when compared to structural factors, is greater for pronouns than for reflexives.

In this paper we focus on three questions left unanswered by our work on English. As will become clear later, Finnish is very well-suited for shedding light on these issues.

(i) Are the source/perceiver effects and the pronoun/reflexive asymmetry English-specific or do they extend to a typologically distinct language as well?

(ii) Is the source/perceiver preference for reflexives and pronouns respectively limited to one particular syntactic structure (RNPs where the pronoun/reflexive is embedded in a PP), or does it also show up in other syntactic configurations? This question will shed light on the question of whether different syntactic structures differ in how impervious they are to the effect of non-structural factors.

(iii) Given that many other languages exhibit greater morphological complexity in their pronominal and reflexive systems than English does, is it the case that morphological differences correspond to interpretational differences? For example, if a language has two reflexive forms, do they differ in their sensitivity to non-structural information? The multiple-factor model's claim that the relative contributions of different factors for each referential form can vary suggests that this could indeed be the case.

To investigate these questions, we conducted two experiments on Finnish. The first one investigates different referential forms in prenominal RNPs and the second one turns to postnominal RNPs.

\section{Experiment 1: Finnish prenominal RNPs}

\subsection{Finnish possessives}

In Finnish, possession is represented by a system of possessive pronouns and possessive suffixes (Px's). In this paper we will focus on the third person possessive suffix, which surfaces as [-nsA] or [-An] (the capital letter indicates that the vowel undergoes vowel harmony and can surface as [a] or [ä]). In third person possessive constructions with pronominal possessors (e.g. 'his car'), the possessive suffix is present on the possessed noun. However, the possessive pronoun itself is null in certain contexts: According to the judgments reported in the literature, when an overt possessive pronoun is not present, then - 'reflexivestyle' - the referent of the subject of the sentence is the possessor (Vilkuna 1996:228-230, Nelson 1998:13)

(10) a. Mari näki hänen autonsa.

Mari-NOM saw s/he-GEN car-ACC-3Px

'Mari $i_{i}$ saw her ${ }_{j}$ (someone else's) car.' 
b. Mari näki autonsa.

Mari-NOM saw $\varnothing$ car-ACC-3Px

'Mari saw her $_{\mathrm{i}}$ (own) car.'

Various analyses have been proposed concerning the Finnish possessive suffix and its relation to the possessive pronoun, and we briefly consider three of them here. One approach analyzes the possessive suffix as an anaphor (e.g. Vainikka (1989), Nelson (1998)). According to this view, third person possessive suffixes are anaphors which must be bound by the subject of the sentence or by a third person possessive pronoun (e.g. Nelson 1998:187-188; see Trosterud 1993 for a somewhat different account of the role of the third person possessive pronoun).

A different analysis is proposed by van Steenbergen (1991), who claims that possessive constructions without an overt possessive pronoun contain an empty element (pro). According to van Steenbergen's analysis, pro is an empty anaphor which can only be bound by the subject and occurs whenever 'it corefers with a c-commanding NP' (van Steenbergen 1991:234). She claims that the possessive suffix marks nominal inflection (van Steenbergen 1991:232). (It is worth noting that in this paper, we will often refer to constructions with no overt possessive pronoun as containing a null possessive pronoun. However, the question of whether such constructions contain a null possessive that acts as a reflexive or whether it is the suffix that acts as the reflexive is not central to our aims in this paper, and our choice of terminology should not be regarded as endorsing one theory over the others.)

A third approach is presented by Toivonen (2000) within Lexical Functional Grammar (LFG). She argues that the third person possessive suffix [-nsA] is 'a single phonological form [that] corresponds to two distinct sets of lexical features' (Toivonen 2000:34). She claims that when the third person possessive suffix occurs without an overt possessive pronoun in a context where the subject is the possessor, the possessive suffix is a subject-bound reflexive pronoun. In contrast, when the suffix occurs in the presence of an overt possessive pronoun and with a subject disjoint in reference, she argues that the possessive suffix is an agreement marker (Toivonen 2000:30).

Despite the important differences between these accounts, it appears that they resemble one another in terms of the predictions they are expected to make regarding the factors that influence the referential properties of reflexives and pronouns. In other words, all three accounts would presumably predict that sentences with no overt possessive pronouns should be influenced by whatever factors influence the referential properties of anaphors (reflexives), and that in sentences with overt possessive pronouns, the referential properties of the possessed NP should be influenced by whatever factors influence the referential properties of pronouns.

Before moving on to the details of the experiment, let us consider another form, besides the overt possessive pronoun, that Finnish offers for indicating reference to a non-subject: the demonstrative pronoun tämän 'this-GENITIVE'. In Finnish, tämä can be used to refer to human referents, and this form has been claimed to be used for human antecedents that are not highly salient (e.g. Varteva 1998, Kaiser \& Trueswell in press). Note that use of genitive tämä does not permit a possessive suffix on the possessed noun.

$$
\begin{aligned}
& \text { c. Mari näki tämän auton. } \\
& \text { Mari-NOM saw this-GEN car-ACC. } \\
& \text { 'Mari }{ }_{i} \text { saw her }{ }_{j} \text { (someone else's) car.' }
\end{aligned}
$$

The fact that both overt pronouns and the demonstrative can be used when the possessor is not the subject raises the question of how they differ. As far as we know, this question has not been investigated in the literature in any depth, although both forms are wide-spread in Finnish language use. Thus, in addition to the aims sketched out above, we also hoped that 
Experiment 1 might be able to shed light on potential differences between the overt pronoun and the demonstrative.

\subsection{Experimental design}

In this experiment, we manipulated verb type (kertoa 'to tell' vs. kuulla 'to hear') and anaphoric form. Participants $(n=32)$ read sentences and chose whose picture was mentioned in the sentence. They were able to choose among four options: subject / object / both are possible / someone else. Sample stimuli and their glosses and translations are shown below.

a. Null/Reflexive with 'told'

Mari kertoi Liisalle muotokuvastaan.

Mari-NOM told Liisa-ALL $\varnothing$ portrait-ELA-3Px

'Mari ${ }_{\mathrm{j}}$ told Liisa ${ }_{\mathrm{k}}$ about her ${ }_{\mathrm{j}}$ portrait.'

a.' Null/Reflexive with 'heard'

Mari kuuli Liisallta muotokuvastaan.

Mari-NOM heard-from Liisa-ABL $\varnothing$ portrait-ELA-3Px

'Mari ${ }_{\mathrm{j}}$ heard from Liisa ${ }_{\mathrm{k}}$ about her $_{\mathrm{j}}$ portrait.'

b. Pronoun

Mari kertoi Liisalle (kuuli Liisalta) hänen muotokuvastaan.

Mari-NOM told Liisa-ALL (heard-from L-ABL) s/he-GEN portrait-ELA-3Px

'Mari told Liisa $_{\mathrm{k}}$ (heard from Liisa ${ }_{\mathrm{k}}$ ) about her ${ }_{\mathrm{k}, \mathrm{i}}$ portrait.'

c. Demonstrative:

Mari kertoi Liisalle (kuuli Liisalta) tämän muotokuvasta.

Mari-NOM told Liisa-ALL (heard-from Liisa-ABL) this-GEN portrait-ELA

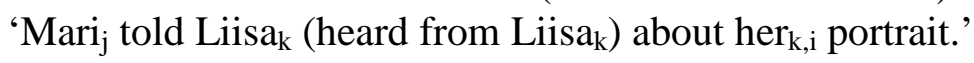

In Finnish, with both kertoa 'to tell' and kuulla 'to hear', the noun 'portrait' is in elative case (ELA). With kertoa 'to tell', the perceiver of information is marked with allative (ALL) case. With kuulla 'to hear from', the source of information is marked with ablative (ABL) case. According to Nikanne (1993), both ALL and ABL are semantic cases, which he distinguishes from the grammatical cases NOM, ACC, PART and GEN. Nikanne argues for the same structural analysis for both ALL and ABL. ${ }^{2}$

\subsection{Predictions}

Let us now consider the predictions that we can make based on the three different approaches mentioned above, namely the pure structural view, the pure discourse/semantic view and the interactive/modulation view (see also Table 1 below). According to the pure structural view, only structural information is relevant and thus the verb manipulation is predicted to have no effect on antecedent choice. More specifically, null possessive pronouns are predicted to refer to the subject, and overt pronouns and demonstratives to the object, regardless of verb. In contrast, the pure discourse semantic view claims that structural information is irrelevant and only source/perceiver preference matter. Thus, the prediction is that 'reflexive-style' null possessive pronouns will be interpreted as referring to the source of information (the subject

\footnotetext{
${ }^{2}$ Thus, Finnish allows us to sidestep the potential structural complication that at first glance seems to arise for English, namely that 'hear from someone' involves a preposition but 'tell someone' does not. Depending on what is assumed to be the syntactic position of the direct object, one could argue that in English the direct object of a verb like tell-unlike the object of a preposition, as with hear from-c-commands the RNP (see Contreras 1984, inter alia) and the direct object is therefore a possible antecedent for a reflexive pronoun and not a possible referent for a pronoun. However, as we show in Kaiser et al (in press), this alternative account for differences between tell and hear from does not receive support from the empirical data from our experiments on English.
} 
with 'tell' and the object with 'hear'), and that overt pronouns will refer to the perceiver of information (the object with 'tell' and the subject with 'hear'). It is not clear what this approach predicts for demonstratives, since they do not fall clearly into the reflexive class or the pronoun class.

\begin{tabular}{|c|c|c|c|}
\hline \multicolumn{4}{|l|}{ Tell } \\
\hline & Null & Pronoun & Demonstrative \\
\hline Syntax & Subject & Object & Object \\
\hline Discourse & Subject & Object & $? ?$ \\
\hline Interactive & Subject & Object & Object \\
\hline \multicolumn{4}{|l|}{ Hear } \\
\hline & Null & Pronoun & Demonstrative \\
\hline Syntax & Subject & Object & Object \\
\hline Discourse & Object & Subject & $? ?$ \\
\hline Interactive & $? ?$ & $? ?$ & Object \\
\hline
\end{tabular}

Table 1. Predictions for Experiment 1.

Finally, let us turn to the interactive/modulation view, which claims that both structural information and discourse/semantic information interact, and that both can influence the choice of antecedent. Let us assume, for reasons of expository ease, that both structural and discourse/semantic factors are weighted equally. As Table 1 shows, according to this view, a null possessive occurring with 'tell' has two kinds of information pushing it towards the subject of the sentence: the binding-theoretic preference towards the sentence subject and the discourse/semantic preference for the source of information. An overt pronoun occurring with 'tell', on the other hand, is pushed towards the object by both Binding Theory and the discourse/semantic perceiver preference. In the case of demonstratives, structurally speaking we expect an object preference, but it is not clear what, if any, effect there will be of the source/perceiver status of potential antecedents.

The picture is more complex with 'hear', however, since structural information and discourse/semantic information are pitted against each other in the case of both null and overt possessive pronouns, as shown in the bottom half of Table 1. Overall, then, we might predict more object choices with null pronouns occurring with 'hear' than null pronouns occurring with 'tell', as well as more subject choices for overt pronouns occurring with 'hear' than overt pronouns occurring with 'tell'. In other words, we predict that in the conditions with 'hear', the discourse/semantic factors will pull overt and null pronouns away from the structurallypredicted antecedents. In the case of demonstratives, as mentioned above, it is not clear what effects, if any, we expect the verb manipulation to have.

\subsection{Results and discussion}

Figure 1 illustrates the results for null possessive pronouns, overt possessive pronouns and demonstrative pronouns with the two verbs. Even a brief glance reveals a striking absence of any verb-driven effect. The pattern of responses is the same with both 'told' and 'heard' regardless of anaphoric form. Considering each anaphoric form in turn, we see that the null possessive pronoun clearly has a strong preference for the preceding subject and the demonstrative has a strong preference for the preceding object. The overt pronouns fall in between these two extremes. Although they are more likely to be interpreted as referring to the preceding object than the preceding subject, this preference is not as strong as in the case of the demonstratives. 


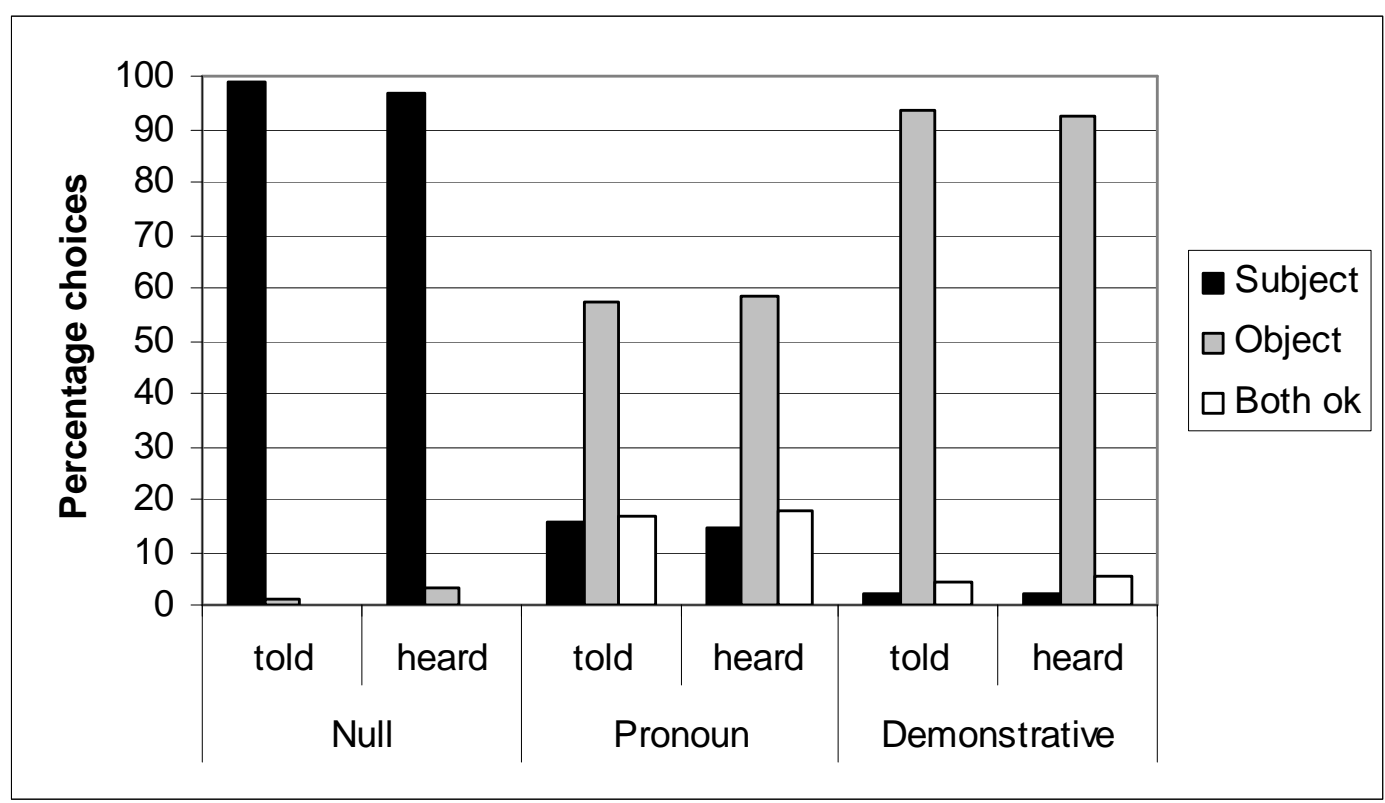

Figure 1. Percentage of antecedent choices for prenominal RNPs in Finnish

The fact that the object preference for possessive pronouns is not as strong as for demonstratives might seem rather surprising in light of the traditional claims that overt possessive pronouns cannot be interpreted as coreferential with the subject of the sentence. However, as Kaiser (2003a) notes, native speaker judgments on the referential properties of overt possessive pronouns seem to not be as clear as the literature might lead one to expect. This effect might be due to the influence of colloquial Finnish / Finnish dialects (see Paunonen 1995, see also Hakulinen et al. 2004:1240), given that in a number of Finnish dialects, it seems that an overt genitive pronoun can be interpreted as being coreferential with the subject as well as the object. (It is well-known that 'it' can be used in many Finnish dialects to refer to human as well as non-human referents without any derogatory connotations, in contrast to its use in Standard Finnish. Standard Finnish is the 'official' form of the language and used in formal writing and public/official speech (e.g. TV newscasts, speeches etc.), but virtually all Finns can speak both standard Finnish and a colloquial dialect of Finnish; they choose which register to use depending on the situation and the modality of language use.)
(12) Liisa
kerto Marille sen
muotokuvasta.
Liisa-NOM told Mari-ALL it-GEN portrait-ELA
'Liisa $a_{\mathrm{j}}$ told Mari about her $_{\mathrm{j}), \mathrm{k}, \mathrm{l}}$ portrait.' (colloquial southern urban Finnish)

As a whole, the results of Experiment 1 support the pure structural view, which posits that the referential properties of pronouns and reflexives are determined by only structural factors. In the prenominal domain in Finnish, in contrast to what was observed for RNPs in English, we see no sign of source/perceiver effects for pronouns or reflexives.

\section{Experiment 2: Postnominal RNPs in Finnish}

In the second experiment, we turn to a different structural configuration, namely postnominal RNPs. These are structurally more parallel to the English RNPs than the Finnish prenominal RNPs investigated in Experiment 1, and thus - if it the case that different syntactic configurations differ in how impervious they are to non-structural factors - we might expect postnominal RNPs in Finnish to be more likely to exhibit source/perceiver effects. 
The Finnish counterparts of 'a picture of herself/her' are shown in (13). Here the contrast is not between absence and presence of an overt genitive pronoun, but rather between the reflexive form itse+Px 'self+Px' (13a) and the pronoun hänestä 's/he-ELATIVE' (13b). (The same reflexive form, itse+Px, with the appropriate case marking, is also used in direct object position in sentence such as "Liisa saw herself.")

$$
\begin{aligned}
& \text { a. Liisa näki kuvan itsestään. } \\
& \text { Liisa-NOM saw picture-ACC self-ELA-3Px } \\
& \text { 'Liisa }{ }_{j} \text { saw a picture of herself } f_{j} \text {.' } \\
& \text { b. Liisa näki kuvan hänestä. } \\
& \text { Liisa-NOM saw picture-ACC s/he-ELA } \\
& \text { 'Liisa } \text { saw a picture of her/him }_{\mathrm{k}} \text {.' }
\end{aligned}
$$

In addition to these 'canonical' forms, we will also consider two other post-nominal reflexive forms, which have not received as much attention in the existing literature, namely a pronoun+reflexive compound form and an emphatic reflexive form. First, let us turn to the pronoun+reflexive compound hänestä itsestään (she/he-ELA self-ELA-3rd.Px) '(about) his/her+himself/herself'. This form appears to be ambiguous between (i) a pronominal with an 'emphatic' reflexive, akin to English structures like he himself, and (ii) a reflexive preceded by an 'emphatic' pronoun (see also Featherston 2002 on the ambiguity of German ihm selbst/ihn selbst). In Experiment 2, in addition to testing whether Finnish pronouns and reflexives in postnominal RNPs are sensitive to the source/perceiver manipulation, we will also test whether the pronoun+reflexive compound patterns more like pronouns or like reflexives in its sensitivity to source/perceiver and structural information, with the aim of shedding light on the question of whether this compound form should be regarded as pronominal or reflexive.

In Experiment 2 we also investigate the referential properties of the emphatic reflexive construction omasta itsestään (own-ELA self-ELA-3rd.Px) '(about) own+himself/herself.' This is presumably an unambiguous reflexive preceded by the emphatic marker 'own,' given that omasta cannot occur independently in post-nominal RNP constructions. Thus, the question arises whether it differs from the standard reflexive form (13a) in its sensitivity to the source status of the antecedent.

\subsection{Experimental design}

In this experiment we manipulated verb type and anaphoric form, as illustrated in (14). A different group of participants $(n=32)$ read sentences and indicated who the joke was about. As in Experiment 1, participants were given four choices: subject / object / both are possible / someone else.

a. Reflexive:

Mari kertoi Liisalle vitsin itsestään.

Mari-NOM told Liisa-ALL joke-ACC self-ELA-3Px

'Mari told Liisa a joke about herself.'

b. Pronoun:

Mari kertoi Liisalle vitsin hänestä.

Mari-NOM told Liisa-ALL joke-ACC she-ELA

'Mari told Liisa a joke about her.'

c. Compound:

...hänestä itsestään

...she-ELA herself-ELA-3rd.Px

...' $\{$ her/him $\}+\{$ herself/himself $\}$ ' 


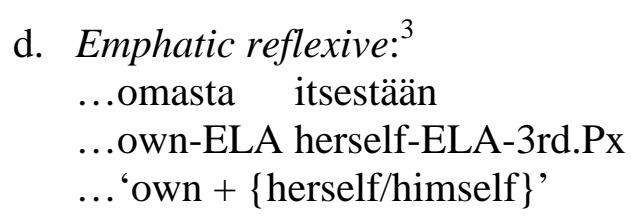

\subsection{Predictions}

In this section we consider the predictions made by the pure structural approach, the pure discourse/semantic approach and the interactive/modulation approach (Table 2). First, according to the pure structural view, we predict that pronouns will be interpreted as referring to the preceding object, regardless of the verb manipulation. Reflexives are predicted to be interpreted as referring to the subject of the sentence, again regardless of the verb, given that reflexives need to be bound by a local c-commanding antecedent. The predictions are less clear for the compound form and the emphatic reflexive. As mentioned above, the compound form seems to be ambiguous between a pronoun and a reflexive, and has not received much attention in existing work. As for the emphatic reflexive, we might expect it to show a subject preference, regardless of verb, since it is presumably a fundamentally reflexive element.

The predictions of the pure discourse/semantic view are different. According to this approach, source/perceiver preferences guide the reference resolution of referential forms in RNPs, and thus we predict that pronouns will opt for the object with tell (perceiver) and the subject with hear (perceiver), and that reflexives will be interpreted as referring to the subject with tell (source) and the object with hear (source). The emphatic reflexive might well pattern like 'regular' reflexives, and again the referential properties of the ambiguous compound form will presumably depend on whether it turns out to be pronominal or reflexive.

\begin{tabular}{|c|c|c|c|c|}
\hline \multicolumn{5}{|l|}{ Tell } \\
\hline & Pronoun & Reflexive & Compound & Emphatic refl \\
\hline Syntax & Object & Subject & $? ?$ & Subject? \\
\hline Discourse & Object & Subject & $? ?$ & Subject? \\
\hline Interactive & Object & Subject & $? ?$ & Subject? \\
\hline \multicolumn{5}{|l|}{ Hear } \\
\hline & Pronoun & Reflexive & Compound & Emphatic refl \\
\hline Syntax & Object & Subject & $? ?$ & Subject? \\
\hline Discourse & Subject & Object & $? ?$ & Object? \\
\hline Interactive & $? ?$ & $? ?$ & $? ?$ & $? ?$ \\
\hline
\end{tabular}

Table 2. Predictions for Experiment 2.

Now, let us turn to the interactive/modulation view. According to this approach, both structural information and discourse/semantic information influence the choice of antecedent. Let us assume, as we did above, that both structural and discourse/semantic factors are weighted equally. As in the first experiment, we find that with tell, both syntactic and discourse factors are pushing in the same direction, but with hear, they are pitted against each other. As a result, we predict that if discourse/semantic factors are playing a role, we should

\footnotetext{
${ }^{3}$ Corpus example:

(a) ....sitä samaa inhoa, jota omaa moraalikäsitystään vastaan rikkonut ihminen tuntee katsoessaan peiliin ja nähdessään kuvan omasta itsestään... (www.virhe.org, posted 12/16/2002)

'...the same hatred that is felt by someone who has acted against his own sense of morality, as he looks into the mirror and sees a picture of himself...'
} 
see more non-BT compatible responses with hear than with tell for both reflexives (perhaps also emphatic reflexives) and pronouns, since in the hear condition the discourse/semantic factors are pulling the referential choices towards the non-BT compatible antecedents (objects in the case of reflexives; subjects in the case of pronouns). The predictions are less clear for the compound form, since its predicted behavior depends on whether it should be analyzed as a pronoun or a reflexive.

\subsection{Results and discussion}

As Figure 2 illustrates, a perceiver preference arises with pronouns. Participants chose subjects as antecedents (i.e., go against Binding Theory) significantly more often with hear than tell. However, the pattern of responses indicates that structural factors also play a role. With tell, we see a clear difference between the rate of object choices and the rate of 'both are possible' choices, but with hear, the numbers are very close. As Table 2 shows, this is a pattern we would expect if both structural and discourse/semantic factors are relevant. In other words, it seems that with hear, the discourse/semantic factors were able to push participants away the object, but did not obliterate the effects of structural factors.

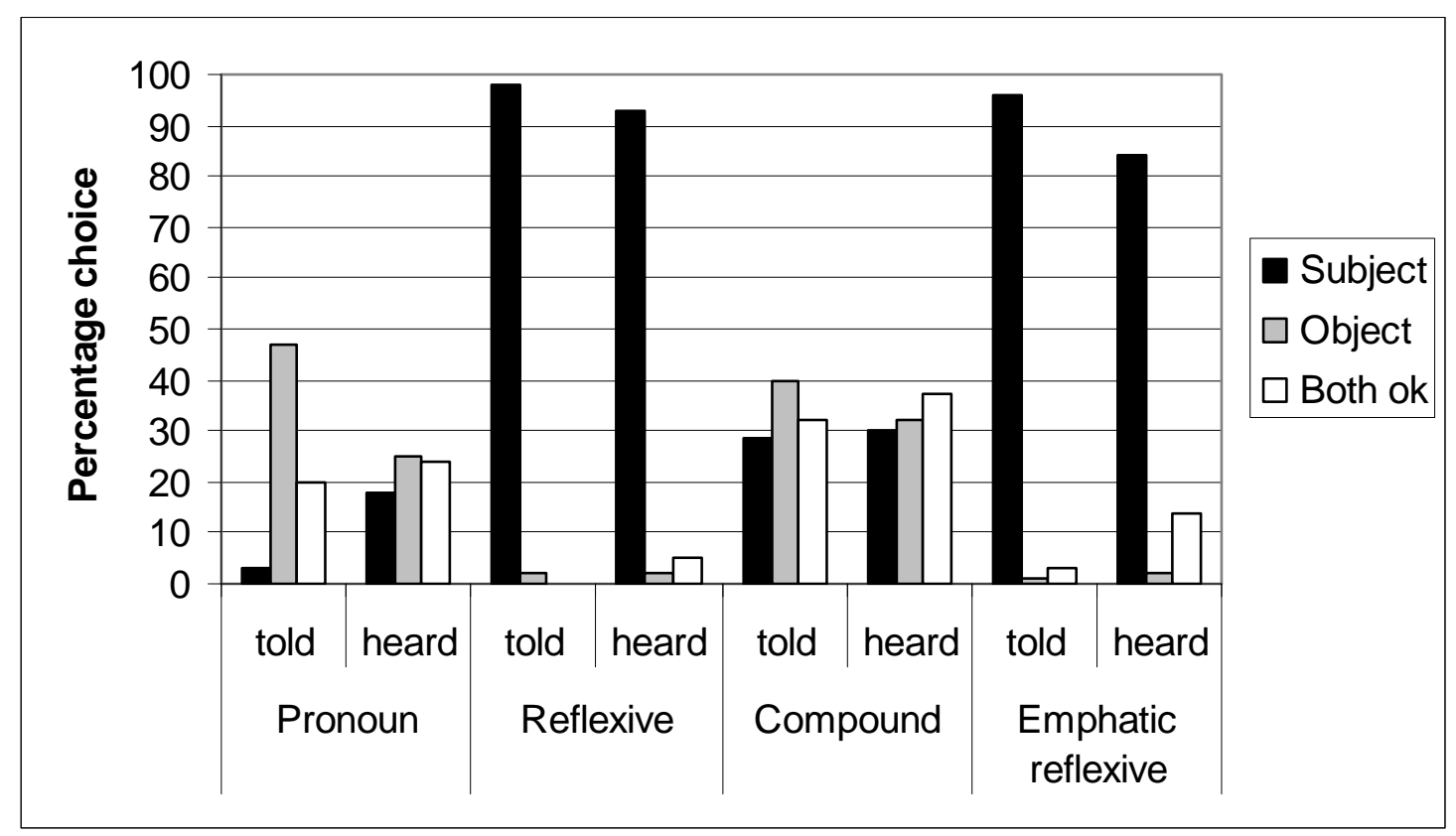

Figure 2. Percentage of antecedent choices for postnominal RNPs in Finnish

In contrast to pronouns, the reflexive and the compound pronoun+reflexive conditions show no clear verb effects. With reflexives, we see a very strong subject preference with both verbs (>90\%), and no effect of the source/perceiver manipulation. Thus, it appears that reflexives, even in postnominal RNPs in Finnish, are sensitive to structural factors only. The compound form, however, is split between subject and object choices with both verbs. This, unfortunately, does not shed as much light on the status of the compound form as one might have hoped. Its referential properties show that it does not pattern like regular reflexives since it does not exhibit an overwhelming subject preference, and thus one could argue that the compound form should not be regarded as fundamentally reflexive in nature. However, its referential properties do not closely match those of pronouns either, although numerically they are in the same direction (slightly more subject choices and 'both' choices with hear than with tell, slightly more object choices with tell than with hear). Thus, one could argue that the compound form appears to pattern somewhat more like a pronoun than a reflexive, but further research is clearly needed. 
Interestingly, the data show that the emphatic reflexive is sensitive to verb manipulation, as there are significantly more 'both' answers with hear than tell. In other words, participants are significantly more likely to consider both subject and object as possible antecedents with hear than with tell. That is, when the object is the source-of-information, it is more likely to be considered. However, given that the source preference shows up as an increase in the number of 'both' responses, rather than as an increase in the number of object responses, suggests that this effect is fairly weak. In contrast to the pronoun condition, where the number of subject choices increased significantly as a result of the verb manipulation, here it is the proportion of 'both' choices that increases. In other words, with the emphatic reflexive, participants are unwilling to abandon the BT-compatible subject choice, even though they are willing to consider an object choice as well if the object is the source.

The results indicate that the effect of the discourse/semantic factors is weaker with emphatic reflexives than with pronouns, which suggests that although the data support the modulation/interactive hypothesis, the structural and the discourse/semantic factors are not weighted equally for pronouns and emphatic reflexives. More specifically, it seems that discourse/semantic factors have a stronger effect on pronouns than on emphatic reflexives, even though structural factors are clearly also playing a role in both cases well. Thus, these data - like our findings for English - support Kaiser's (2003b) and Kaiser \& Trueswell's (in press) multiple-factor model which claims that different referential forms are sensitive to different kinds of information to different degrees.

\section{Conclusions}

In this paper we reported on two experiments that were designed to investigate what kinds of information contribute to the interpretation of pronouns and reflexives in Finnish RNPs. The results show that different syntactic configurations differ in their sensitivity to non-structural factors: Experiment 1, which investigated prenominal RNPs, showed no source/perceiver effects, but such effects arose in Experiment 2, which looked at postnominal RNPs. The findings of Experiment 2 indicate that the source preference for reflexives and the perceiver preference for pronouns (discussed by Kuno (1987) and Tenny (2003), and found experimentally by Kaiser et al. in press for English) also arise in a typologically different language, i.e. these effects do not appear to be a purely English-only phenomenon.

As the results of Experiment 2 show, morphological differences in Finnish reflexives seem to correlate with interpretational differences. The different reflexive forms differ in their sensitivity to the verb manipulation, which means that a fine-grained approach is necessary for capturing the referential properties of different anaphoric forms. Such a finding is fully compatible with the multiple-factor model, which assumes that multiple factors can play a role in reference resolution, and crucially also posits that the relative contributions of these factors can be different for different anaphoric forms (Kaiser 2003b, Kaiser \& Trueswell in press). This approach can also straightforwardly capture the finding that in Finnish, as in English, discourse/semantic factors contribute more to the interpretation of pronouns than to the interpretation of reflexive-type elements.

As a whole, our data from Finnish provide further support for a multiple-factor model of reference resolution. Hopefully future work can further investigate the validity of the multiple-factor model in other languages and other domains, and also shed light on whether representational NPs in languages other than Finnish and English show similar kinds of source/perceiver effects. 


\section{References}

Brown-Schmidt, S., Byron, D. \& Tanenhaus, M.K. (2005). Beyond salience: interpretation of personal and demonstrative pronouns. Journal of Memory and Language 53:292-313.

Cantrall, William R. (1974) Viewpoint, Reflexives, and the Nature of Noun Phrases. The Hague: Mouton.

Chomsky, N. (1981). Lectures on Government and Binding. Foris. Dordrecht.

Chomsky, N. (1986). Barriers. MIT Press. Cambridge, Mass.

Contreras, H. 1984. A Note on Parasitic Gaps. Linguistic Inquiry 15:698-701.

Featherston, S. 2002. Coreferential objects in German: Experimental evidence on reflexivity. Linguistische Berichte 192:457-484.

Hakulinen, A., Vilkuna, M., Korhonen, R., Koivisto, V., Heinonen T. R. \& Alho, I. 2004. Iso suomen kielioppi. SKS: Helsinki.

Kaiser, E. 2003a. Encoding (Non)Locality in anaphoric relations. In Nelson, D. \& Manninen, S. (eds.) Generative Approaches to Finnic and Saami Linguistics, 269-293. Stanford: CSLI Publications.

Kaiser, E. 2003b. The quest for a referent: A crosslinguistic look at referent resolution. Ph.D. dissertation, University of Pennsylvania.

Kaiser, E., Runner, J.T., Sussman, R.S. \& Tanenhaus, M.K. (in press). The Interpretation of Pronouns and Reflexives in Picture Noun Phrases: Effects of Non-structural Factors. To appear in A. Alcazar, R. Mayoral Hernandez \& M.T. Martinez (eds), Proceedings of the Western Conference on Linguistics 2004. Fresno: California State University at Fresno.

Kaiser, E., Runner, J.T., Sussman, R.S. \& Tanenhaus, M.K. 2005. Whose picture? Reference resolution in and out of picture NPs. Poster presented at the 18th Annual CUNY Conference on Human Sentence Processing. March 31-April 2, 2005. Tucson, AZ.

Kaiser, E. \& J.C. Trueswell (in press) Investigating the interpretation of pronouns and demonstratives in Finnish: Going beyond salience. To appear in E. Gibson \& N. Pearlmutter (eds), The processing and acquisition of reference. MIT Press.

Keller, F. \& Asudeh, A. 2001. Constraints on linguistic coreference: Structural vs. pragmatic factors. Proc 23rd Conf. of the Cog Sci Soc, 483-488.

Kuno, S. 1987. Functional Syntax: Anaphora, discourse \& empathy. Chicago: Chicago University Press.

Nelson, D. 1998. Grammatical Case Assignment in Finnish. New York: Garland

Nikanne, U. 1993. On assigning semantic cases in Finnish. In A. Holmberg \& U. Nikanne (eds.) Case and other functional categories in Finnish syntax, pp.75-88. Berlin/New York: Mouton de Gruyter.

Paunonen, H. 1995. Puhesuomen muuttuva omistusjärjestelmä. Virittäjä 99. 
Pollard, C. \& Sag, I. 1992. Anaphors in English and the scope of Binding Theory. Linguistic Inquiry 23:261-303.

Reinhart, T. \& Reuland, E. 1993. Reflexivity. Linguistic Inquiry 24:657-720.

Runner, J.T., Sussman, R.S. \& Tanenhaus, M.K. (to appear). The Influence of Binding Theory on the On-Line Reference Resolution of Pronouns, in Proceedings of North Eastern Linguistic Society 34.

Runner, J.T., Sussman, R. S. \& Tanenhaus, M.K. 2003. Assignment of reference to reflexives and pronouns in picture noun phrases: evidence from eye movements. Cognition 89(1):B1-B13.

Runner, J. T., Sussman, R. S. \& Tanenhaus, M. K. 2002. Logophors in Possessed Picture Noun Phrases. In L. Mikkelsen and C. Potts, eds., WCCFL 21 Proceedings, pp. 401414. Somerville, MA: Cascadilla Press.

Sells, P. 1987. Aspects of Logophoricity. Linguistic Inquiry 18 (3):445-479.

van Steenbergen, M. 1991. Long-distance binding in Finnish. Long-distance anaphora, ed. J. Koster and E. J. Reuland, 231-244. Cambridge: Cambridge University Press.

Tenny, C. 1996. Short distance pronouns and locational deixis. LinguistList on-line conference.

Tenny, C. 2003. Short distance pronouns, argument structure, and the grammar of sentience. Ms., 2003.

Tenny, C. 2004. Short Distance Pronouns in Representational NPs and a Grammar of Sentience. Ms.

Toivonen, I. 2000. The Morphosyntax of Finnish Possessives. Natural Language and Linguistic Theory 18(3):579-609.

Trosterud, T. 1993. Anaphors and Binding Domains in Finnish. In A. Holmberg \& U. Nikanne (eds), Case and Other Functional Categories in Finnish Syntax, pp.225-244. Berlin: Mouton de Gruyter.

Vainikka, A. 1989. Deriving Syntactic Representations in Finnish. Doctoral dissertation, University of Massachusetts.

Varteva, A. 1998. Pronominit hän ja tämä tekstissä. Virittäjä 2/1998, 202-223

Vilkuna, M. (1996). Suomen lauseopin perusteet. Helsinki: Edita

Zribi-Hertz, A. 1989. Anaphor Binding and Narrative Point of View English Reflexive Pronouns in Sentence and Discourse. Language 65(4): 695-727. 